\title{
Enuresis and Attention Deficit Hyperactivity Disorder (ADHD) in Children and Adolescents Department of Psychiatry
}

\section{Quintero J}

Department of Psychiatry and Medical Psychology, University Hospital Infanta Leonor, Complutense University of Madrid, Spain

*Corresponding author: Department of Psychiatry and Medical Psychology, University Hospital Infanta Leonor, Complutense University of Madrid, Spain, Tel: 570-822-1676; E-mail: fjquinterog@salud.madrid.org

Received date: 30 December, 2013; Accepted date: 08 February, 2014; Published date: 13 February, 2014

Copyright: (C) 2014 Quintero J. This is an open-access article distributed under the terms of the Creative Commons Attribution License, which permits unrestricted use, distribution, and reproduction in any medium, provided the original author and source are credited.

\begin{abstract}
Attention Deficit Hyperactivity Disorder (ADHD) is the most prevalent psychiatric disorder in children; perhaps relationship between ADHD and enuresis is still unknown. Comorbidity confers an additional risk to the simple symptomatic expression, and a greater complexity from the diagnostic and therapeutic viewpoints. The primary endpoint was to find out the Comorbidity between enuresis and ADHD in our population. A retrospective, casecontrol study was designed. This study analyzed retrospectively a total of 1536 clinical histories of new patients (5-17 years of age) attending the outpatient clinic from 2002 to 2007. Patients with ADHD (according to DSM-IV criteria) were selected, and the presence of comorbidity with nocturnal enuresis or sphincter control was examined. We observed that nocturnal enuresis is a significant and common comorbid condition with ADHD (OR=2.27). We also found that ADHD is associated to a greater probability of lack of nocturnal sphincter control at 4 years of age [OR: $5.3995 \% \mathrm{Cl}: 3.70-7.86 ; \mathrm{p}<0.05]$ and to experience enuresis from 5 years of age [OR: $2.2795 \% \mathrm{Cl}: 1.17-4.3$; $p<0.05]$. This association is both age- and sex-dependent. Because of the potential implications of both disorders on the physical and emotional development, routine screening for nocturnal enuresis should be required in children diagnosed with ADHD, and the potential presence of ADHD would have to be explored in patients with delayed nocturnal control of bladder sphincters or nocturnal enuresis.
\end{abstract}

Keywords: Enuresis; ADHD; Sphincter control; Comorbidity;Neuro-Development

\section{Introduction}

ADHD is a clinically defined disorder validated across different races and cultures, with a stable prevalence ranging from $3 \%-10 \%$. It has been included among the most prevalent diseases in childhood, and undoubtedly the most prevalent psychiatric disorder [1]. ADHD combines at different levels three main groups of symptoms: attention deficit, hyperactivity, and impulsivity. The DSM or ICD classifications should be followed to define the ADHD subtype depending on how such groups of symptoms are combined $[2,3]$.

ADHD pathogenesis is related to genetic, neurobiological, and environmental factors, the combination of which is responsible for the final clinical expression. This condition occurs relatively early in development, which contrasts with the theories explaining ADHD as a syndrome of an environmental origin [3].

The association of ADHD and enuresis has been studied, by authors like Biederman et al. reporting the high co morbidity between enuresis and ADHD, reporting an association between both disorders (Chisquare $=11.5, \mathrm{p}<0.001 ; \mathrm{OR}=3.0$ ) [4]. In another study conducted in the US involving 1136 children aged 811 years, a strong association was found between ADHD and enuresis (OR: 2.88; 95\%CI 1.26-6.57) [5]. Baeyens et al. selected a total of 120 children aged 6-12 years with enuresis and found that $15 \%$ of them had ADHD combined subtype and $22.5 \%$ of them had ADHD inattentive type [6]. Recently, a study on the co-morbidity of enuresis in children with ADHD has been published that demonstrated the relationship between enuresis and opposition defiant disorders [7]
Development of micturition control is considered to depend on maturation processes of the nervous system. Several studies have analyzed this relationship in recent years $[6,8,9]$. According to the American Psychiatric Association, primary nocturnal enuresis is defined as a failure of voluntary control of the urethral sphincter in a child older than 5 years who has never been able to reach an adequate sphincter control in the past. The prevalence of enuresis is $15 \%-20 \%$, and the condition resolves spontaneously in $15 \%$ of cases every year [10]. Only $1 \%-2 \%$ of adolescents have enuresis at 15 years. In the US, enuresis affects 5-7 million children [11]. It is also known that children with enuresis who required specialized (tertiary) care have a 3.4-fold greater chance of suffering ADHD than those not requiring such care [12]. Families were also found to have no concern for seeking treatment for enuresis despite its potential adverse effects on the emotional health of children [6]. It is also known that children with enuresis who required specialized (tertiary) care have a 3.4-fold greater chance of suffering ADHD than those not requiring such care [13].

The primary endpoint of our study was to analyse the comorbidity between enuresis and ADHD in Spanish population. The secondary endpoint was to look for presence of the acquisition of sphincter control after 4 years age, and ADHD and enuresis in children.

\section{Materials and Methods}

A retrospective, case-control study was designed. The study was conducted at a multidisciplinary referral centre in the Community of Madrid (Spain) during the period 2002 to 2007

Male and female patients aged $\geq 5$ years with a diagnosis of ADHD or enuresis were eligible for inclusion, all of them with similar sociodemographic and clinical characteristics. A cohort of 1.536 patients 
Page 2 of 4

was found and two age groups of patients (6-11 and 12-18 years old) were performed.

ADHD was diagnosed according to criteria specified in the Diagnostic and Statistical Manual of Mental Disorders 4th Edition (DSM-IV) evaluating the evolutive characteristics of the patients and fulfilling at least 6 of the inattention criteria and/or 6 of the hyperactive-impulsivity criteria. All of them were followed up during the 5-year period, between 2002 and 2007.

The information included in the clinical histories was completed through interviews carried out by psychiatrist and/or clinical psychologists, since a psychological test was carried out on all the patients included in this study. During each interview and after informed consent was obtained, both parent's and children's opinions were evaluated. A specific questionnaire was designed to collect information in standardized hard copy format. The retrospective and consecutive information collected by a psychiatrist included demographic data (gender and age) and clinical data (diagnosis of enuresis and bladder sphincter control), as well as personal and family history of the patient (comorbidities: learning disabilities, reading disorder, anxiety, phobias, depressive disorders, somatomorphic disorders, adaptation disorder, behaviour and emotional problems).

\section{Statistical analysis}

Relative frequencies and 95\% confidence intervals were estimated for descriptive data, as well as the mean and standard deviation for quantitative variables.

In order to estimate the sample size required to conduct the study, it was assumed that, in a worst case scenario, the prevalence of enuresis in the population is $3.8 \%$ and the association between enuresis and ADHD as established in a recent study at an $\mathrm{OR}=2.88$ (95\%CI:1.26-6.57) [14]. A 95\% power was established, and we estimated the final sample size required as 1,500 patients.

To study the association between ADHD with sphincter control by the age of 4 years and nocturnal enuresis, the odds ratio (OR) was calculated using a Mantel-Haenszel test of association to determine its statistical significance. To assess the potential influence of gender and age on the association between the above mentioned variables, the OR was calculated in each stratum and was compared using a Wald homogeneity test. An integrated database was created in Excel format. SPSS 14.0 software was used for statistical processing of information.

\section{Results}

1,536 clinical histories were included in the analysis. Of these, 570 patients had a primary diagnosis of ADHD (21 with enuresis), while 966 (16 with enuresis) had no primary diagnosis of ADHD.

ADHD was diagnosed in a much higher proportion of males (46.95\%) as compared to females $(19,53 \%)$. It may thus be stated that the probability of consulting and being subsequently diagnosed with ADHD is 3.71; $\mathrm{p}<0.0001$-fold greater in males as compared to females $(\mathrm{OR}=3.71$; 95\%CI: 2.93-4.71; $\mathrm{p}<0.0001)$ (Table 1).

\begin{tabular}{|l|l|l|l|}
\hline & $\begin{array}{l}\text { Patients with } \\
\text { ADHD }\end{array}$ & $\begin{array}{l}\text { Patients without } \\
\text { ADHD }\end{array}$ & $\begin{array}{l}\text { OR } \\
(95 \% \mathrm{Cl})\end{array}$ \\
\hline Female & 122 & 486 & $\begin{array}{l}3.64(2.91- \\
4.56)\end{array}$ \\
\hline
\end{tabular}

\begin{tabular}{|l|l|l|l|}
\hline Male & 448 & 448 & \\
\hline
\end{tabular}

Table 1: Association of ADHD and sex. OR=Odds Ratio. $\mathrm{CI}=$ confidence interval.

\section{Sphincter control before 4 years of age}

In our study, among patients with ADHD aged 4 years, $80.7 \%$ have enuresis an $19.3 \%$ do not. By contrast, in the same age group, patients without ADHD, only $4.2 \%$ have enuresis and $95.8 \%$ do not.

The chance of no nocturnal sphincter control at 4 years is therefore 5.39-fold greater in children with ADHD as compared to those without ADHD (OR=5.39; 95\%CI: 3.70-7.86) $(\mathrm{p}<0.0001)($ Table 2).

\begin{tabular}{|l|l|l|l|}
\hline & $\begin{array}{l}\text { Patients without } \\
\text { ADHD }\end{array}$ & $\begin{array}{l}\text { Patients with } \\
\text { ADHD }\end{array}$ & $\begin{array}{l}\text { OR } \\
(95 \% \mathrm{Cl})\end{array}$ \\
\hline Nocturnal sphincter control & $925(95.8 \%)$ & $460(80.7 \%)$ & \\
\cline { 1 - 3 } $\begin{array}{l}\text { No nocturnal sphincter } \\
\text { control }\end{array}$ & $41(4.2 \%)$ & $110(19.3 \%)$ & $\begin{array}{l}5.39[3.70-7 \\
.86]\end{array}$ \\
\hline
\end{tabular}

Table 2: Nocturnal sphincter control at 4 years of age. OR=Odds Ratio. $\mathrm{CI}=$ confidence interval.

\section{Association of ADHD and enuresis}

The prevalence of enuresis was $3.68 \%$ in patients with ADHD and $1.66 \%$ in patients without ADHD. It may therefore be stated that the chance of suffering from nocturnal enuresis is 2.27 -fold greater in children with ADHD as compared to controls (OR=2.27; 95\%CI: 1.17-4.39; $\mathrm{p}<0.012$ ) (Table 3).

\begin{tabular}{|l|l|l|l|}
\hline & $\begin{array}{l}\text { Patients without } \\
\text { ADHD }\end{array}$ & $\begin{array}{l}\text { Patients with } \\
\text { ADHD }\end{array}$ & OR $(95 \% \mathrm{Cl})$ \\
\hline With enuresis & $16(1.65 \%)$ & $21(3.68 \%)$ & \multirow{2}{*}{$2.27[1.17-4.38]$} \\
\cline { 1 - 3 } Without enuresis & $950(98.35 \%)$ & $549(96.32 \%)$ & \multicolumn{2}{|c|}{} \\
\hline
\end{tabular}

Table 3: Enuresis in patients with ADHD. OR=Odds Ratio. $\mathrm{CI}=$ confidence interval.

The association of enuresis and ADHD appears to be agedependent, the chance of patients with ADHD suffering from enuresis is much greater among those aged $12-18$ years (OR: 6.22; 95\%CI: $1.54-25.09$ ] than among patients aged 6 to 11 years $(\mathrm{OR}=0.91 ; 95 \% \mathrm{CI}$ : $0.42-1.95) \chi^{2}$ wald $=12.25, \mathrm{p}=0.0021$.

The association also appeared to be gender-dependent. Thus, the chance of patients with ADHD suffering enuresis was higher in males (OR: 1.82; 95\%CI: $0.88-3.77$ ] than in females (OR: 0.99 ; $95 \% \mathrm{CI}$ : $0.11-8.99] \chi 2$ wald $=0.261, \mathrm{p}=0.605$.

\section{Discussion}

To our Knowledge, this is one of the first European studies -and the one including the largest sample- conducted to assess the prevalence of nocturnal enuresis and bladder control in patients with and without a diagnosis of ADHD using standardized diagnostic criteria.

Our study found prevalence greater rates of enuresis in children with ADHD compared to controls (Table 3). The association of enuresis and ADHD appears to be age-dependent, the chance of 
patients with ADHD suffering enuresis is much greater among those aged 12-18 years than among patients aged 6 to 11 years [15]. The results of our study reinforce that attention deficit hyperactivity disorder (ADHD) is a significant and frequent comorbid disorder with nocturnal enuresis. Our data support the results of a similar study recently conducted in the United States, which found that the chance of suffering enuresis was 2.88 -fold higher in patients diagnosed with ADHD [14], although it should be noted that our study included patients of a wider age range and the prevalence of nocturnal enuresis declined with age in all groups. Also another finding were gender differences, observing that enuresis was higher in males than in females.

Several authors attribute such relationship to a delayed maturation of certain structures of the central nervous system $[14,16]$. Such explanation is supported by the abnormalities found in both conditions in the encephalogram and with magnetoencephalography imaging technique (MEG) [17]. In addition, children with ADHD have markedly higher rates of incontinence, constipation, urgency, infrequent voiding, nocturnal enuresis, and dysuria as compared to those with no ADHD which makes a common origin of all these conditions more feasible [18].

Another significant finding of our study is the age effect on the comorbidity of enuresis with ADHD, so that the chance of experiencing both problems was higher in children over 12 years of age (6.22; 95\%CI: 1.5425.09) than in children under 12 years, in whom the relationship appeared to be virtually non-existent $(0.91 ; 95 \% \mathrm{CI}$ : $0.42-1.95)$. This may be due to either a true relationship between age and the association between both conditions under study or to the fact that ADHD symptoms are more evident as the child grows, thus increasing the frequency with which they are diagnosed, or simply to the fact that the relationship becomes more evident at age groups where the presence of one of the problems (enuresis) significantly decreases. In the prevalence study of ADHD in children with nocturnal enuresis aged 6-12, Baeyens et al found that the older the children, the higher the prevalence of the inattentive subtype of $\mathrm{ADHD}$, and the hypothesis of attention problems as a risk factor for difficult to cure nocturnal enuresis was likely [19].

The other finding in our study, was a greater association of ADHD and enuresis in males (1.82; 95\%CI: 0.88-3.77] as compared to females (0.99; 95\%CI: 0.11-8.99), appears to be easier to explain, since it is well known that both ADHD and enuresis are more frequent in males [14].

Management of nocturnal enuresis is different in children with ADHD as compared to those without ADHD, and is directly affected by various factors, including compliance [20]. Current management of nocturnal enuresis is based on the use of: 1) Drug interventions including antidiuretic hormone analogues i.e. desmopressin (with special precautions to avoid the risk of hyponatraemia as stated by the FDA in April 2007), tricyclic antidepressants (i.e. imipramine) and anticholinergics. 2) Behavioral interventions such as alarms. However, a substantial number of patients do not fully respond to none of these interventions despite optimum medication management and dosage. In the two-year study of Baeyens et al, it was found that enuresis was more difficult to resolve in children who had ADHD as compared to healthy controls (OR: 3.17; 95\%CI 1,31-7,67). While there are many factors possibly conditioning the ability to cure enuresis, methylphenidate or atomoxetine may be two of them [21]. A recent study showed that the percentage of children with enuresis decreased by half after methylphenidate administration [22]. This fact may have therapeutic implications within the complex framework treatment of enuresis.

\section{Conclusion}

It should be stated that ADHD is a significant and common comorbid disorder with nocturnal enuresis ( $\mathrm{OR}=2.27$; 95\%CI: 1.17-4.39), and both conditions have consequences for child development and quality of life so we deem it is appropriate to screen children diagnosed with ADHD for enuresis and vice versa to ensure a global approach to each patient. More studies are needed to confirm our data.

\section{References}

1. Millichap JG (2008) Etiologic classification of attention-deficit/ hyperactivity disorder. Pediatrics 121: 358-365.

2. DasBanerjee T, Middleton FA, Berger DF, Lombardo JP, Sagvolden T, et al. (2008) A comparison of molecular alterations in environmental and genetic rat models of ADHD: a pilot study. Am J Med Genet B Neuropsychiatr Genet 147B: 1554-1563.

3. Renner TJ, Gerlach M, Romanos M, Herrmann M, Reif A, et al. (2008) Neurobiology of attention-deficit hyperactivity disorder. Nervenarzt 79: 771-781.

4. Biederman J, Santangelo SL, Faraone SV, Kiely K, Guite J, et al, (1995) Clinical correlates of enuresis in ADHD and non-ADHD children. J Child Psychol Psychiatry 36: 865-877.

5. de Quirós GB, Kinsbourne M, Palmer RL, Rufo DT, et al.(1994) Attention deficit disorder in children: three clinical variants. J Dev Behav Pediatr 15: 311-319.

6. Baeyens D, Roeyers H, D'Haese L, Pieters F, Hoebeke P, et al. (2006) The prevalence of ADHD in children with enuresis: comparison between a tertiary and non-tertiary care sample. Acta Paediatr 95: 347-352.

7. Pliszka SR (2003) Psychiatric comorbidities in children with attention deficit hyperactivity disorder: implications for management. Paediatr Drugs 5: 741-750.

8. Baeyens D, Roeyers H, Van Erdeghem S, Hoebeke P, Vande Walle J, et al. (2007) The prevalence of attention deficit-hyperactivity disorder in children with nonmonosymptomatic nocturnal enuresis: a 4-year followup study. J Urol 178: 2616-2620.

9. von Gontard A, Freitag CM, Seifen S, Pukrop R, Röhling D, et al. (2006) Neuromotor development in nocturnal enuresis. Dev Med Child Neurol 48: 744-750.

10. Freitag CM, Röhling D, Seifen S, Pukrop R, von Gontard A, et al. (2006) Neurophysiology of nocturnal enuresis: evoked potentials and prepulse inhibition of the startle reflex. Dev Med Child Neurol 48: 278-284.

11. Cendron M (1999) Primary nocturnal enuresis: current. Am Fam Physician, 59: 1205-14.

12. Ramakrishnan K (2008) Evaluation and treatment of enuresis. Am Fam Physician 78: 489-496.

13. Baeyens D, Roeyers H, Naert S, Hoebeke P, Vande Walle J, et al. (2007) The impact of maturation of brainstem inhibition on enuresis: a startle eye blink modification study with 2-year followup. J Urol 178: 2621-2625.

14. Shreeram S, He JP, Kalaydjian A, Brothers S, Merikangas KR, et al. (2009) Prevalence of enuresis and its association with attention-deficit/ hyperactivity disorder among U.S. children: results from a nationally representative study. J Am Acad Child Adolesc Psychiatry48: 35-41.

15. Abrams P, Andersson KE, Birder L, Brubaker L, Cardozo L, et al. (2010) Fourth International Consultation on Incontinence Recommendations of the International Scientific Committee: Evaluation and treatment of urinary incontinence, pelvic organ prolapse, and fecal incontinence. Neurourol Urodyn 29: 213-240.

16. Kohyama J, Kumada S, Shimohira M, Araki S, Itoh M, et al. (2000) Nocturnal enuresis and the pontine reticular formation. Eur Urol 38: 631-634. 
Citation: Quintero J (2014) Enuresis and Attention Deficit Hyperactivity Disorder (ADHD) in Children and Adolescents Department of Psychiatry. Clinics Mother Child Health 11: 160. doi:10.4172/2090-7214.1000160

Page 4 of 4

17. Fernández A, Quintero J, Hornero R, Zuluaga P, Navas M, et al. (2009) Complexity analysis of spontaneous brain activity in attention-deficit/ hyperactivity disorder: diagnostic implications. Biol Psychiatry 65: 571-577.

18. Duel BP, Steinberg-Epstein R, Hill M, Lerner M, et al. (2003) A survey of voiding dysfunction in children with attention deficit-hyperactivity disorder. J Urol170:1521-1523.

19. Baeyens D, Roeyers H, Demeyere I, Verté S, Hoebeke P, et al. (2005) Attention-deficit/hyperactivity disorder (ADHD) as a risk factor for persistent nocturnal enuresis in children: a two-year follow-up study. Acta Paediatr 94: 1619-1625.
20. Crimmins CR, Rathbun SR, Husmann DA (2003) Management of urinary incontinence and nocturnal enuresis in attention-deficit hyperactivity disorder. J Urol 170: 1347-1350.

21. Shatkin JP (2004) Atomoxetine for the treatment of pediatric nocturnal enuresis. J Child Adolesc Psychopharmacol 14: 443-447.

22. Tomás Vila M, Aleu Pérez-Gramunt M, Beseler Soto B, Benac Prefasi M, Pantoja Martínez J, et al. (2010) Methylphenidate and sleep: Results of a multicentre study on a population of children with attention deficit hyperactivity disorder. An Pediatr (Barc) 73: 78-83. 